\title{
Una mirada crítica a los objetivos de desarrollo sostenible a partir de una experiencia realizada por estudiantes de primaria: ¿ser o no ser, esa es la cuestión?
}

\author{
A Critical Look at the Sustainable Development Goals \\ from an Experience Carried Out by Elementary School \\ Students: To Be or Not to Be, Is That the Question
}

\author{
Alynne de Oliveira', Beatriz Rodrigues ${ }^{1}$, Victória Rodrigues' \\ Kelly Pinheiro dos Santos ${ }^{1}$, Laísa Maria Freire ${ }^{1}$, Cristian Merino² \\ 1 Universidade Federal do Rio de Janeiro \\ 2 Pontificia Universidad Católica de Valparaíso
}

\begin{abstract}
Resumen
El presente trabajo analiza limitaciones, posibilidades, condicionantes y sustratos cualitativos para la significación de planteamientos de sostenibilidad en discursos globales como los 17 Objetivos de Desarrollo Sostenible (ODS). Para eso, se realizó un taller de educación ambiental con estudiantes de primaria en dos escuelas públicas de Río de Janeiro, Brasil. En cada taller, los estudiantes $(\mathrm{n}=103)$ fueron divididos en cinco grupos, cada uno de los cuales recibió un kit con una fotografía de una obra de arte, una fotografía de Río de Janeiro y una noticia. Producto de la actividad los participantes elaboraron un dibujo acerca de la construcción de un mundo sostenible. Para la identificación de sus dibujos se recurrió a análisis cualitativo a través de redes sistémicas y clasificación en niveles de representación. Los resultados indican que los estudiantes relacionan algunos ODS entre sí, aunque los dibujos se concentraron en el nivel de representación como descripción. En la Escuela 2 se observaron mayores sofisticaciones y complejidad en los dibujos, los que incluyeron aspectos simbólicos, sintácticos y semánticos. Finalmente, las conclusiones indican que los dibujos incluyen verbos imperativos, prescribiendo modos de cambio y acción de los cuales nińas y niños se hacen partícipes.
\end{abstract}

Palabras clave: análisis de dibujos, educación ambiental, ecopedagogía, objetivos del desarrollo sostenible, sostenibilidad.

Correspondencia a:

Alynne de Oliveira

Laboratório de Limnologia da UFRJ. Avenida Carlos Chagas Filho, 373, Edifício do CCS, Bloco A, Sub-Solo, Sala A0-008 - Cidade Universitária, Ilha do Fundão, Rio de Janeiro/RJ CEP: 21.949-900, Brasil.

oli.alynne@gmail.com

Financiamiento asociado: Proyecto de extensión "Vida en el agua, agua en

la vida: entrelazando la educación ambiental y la divulgación de la ciencia, la universidad y la escuela" - Universidad Federal de Río de Janeiro (UFRJ); Proyecto PIBID/CAPES 2018-2019 Número del proceso: 88882.215740/201801; Coordinación para el Mejoramiento del Personal de Educación Superior Brasil (CAPES/Print) - Número del proceso: 88881.312004/2018-01; Programa Institucional de Internacionalización (CAPES/PRINT) Número de proceso: 88887.466572/2019-00; Proyecto Fondecyt 1180619 (ANID, Gobierno de Chile).

(C) 2020 PEL, http://www.pensamientoeducativo.org - http://www.pel.cl

ISSN:0719-0409ＤDI:203.262, Santiago, Chile doi: 10.7764/PEL.57.2.2020.7 


\begin{abstract}
This study analyzes the limitations, possibilities, conditioning factors, and qualitative substrates for the significance of sustainability approaches in global discourses such as the 17 Sustainable Development Goals (SDG). In order to do this, an Environmental Education workshop was held with elementary students in two public schools in Rio de Janeiro, Brazil. The students $(\mathrm{n}=103)$ were divided into five groups. Each group received a kit containing a photograph of a work of art, a photograph of Rio de Janeiro, and a news report. As a result of the activity, the participants made a drawing about the construction of a sustainable world. In order to identify their drawings, a qualitative analysis strategy was used through systemic networks and classification into levels of representation. The results indicate that the students relate some SDGs to each other, although the drawings concentrated on the level of representation as description. In School 2, greater sophistication and complexity are observed in the drawings, which include symbolic, syntactic, and semantic aspects. Finally, the conclusions indicate that the drawings include imperative verbs, prescribing modes of change and action for the children to participate.
\end{abstract}

Keywords: ecopedagogy, environmental education, drawing analysis, sustainability, sustainable development goals.

\title{
Introducción
}

Esta investigación acerca de la práctica educativa propone la discusión respecto de los límites, las posibilidades, las condicionantes y los sustratos cualitativos para la significación de planteamientos de sostenibilidad en discursos globales, a partir de la presentación, discusión y reflexión de experiencias de un taller de educación ambiental en dos escuelas municipales de Río de Janeiro, Brasil. Realizados en 2019, estos talleres formaron parte de la feria de ciencias de las escuelas y participaron aproximadamente 100 estudiantes de primaria. El trabajo dialoga con los acuerdos globales para la sostenibilidad y entiende que la educación ambiental en la escuela interpreta y traduce dichos acuerdos, así como también define pedagogías y enfoques para ciertos temas.

En el rango de perspectivas pedagógicas respecto de la cuestión ambiental, podemos situar algunos abordajes más conservadores de la relación entre el ser humano y la naturaleza y otros más radicales, los que se caracterizan por contener distintas macrotendencias político-pedagógicas de la educación ambiental (Layrargues \& Lima, 2014). Las visiones más radicales pueden ser reconocidas por su compromiso con cambios en los modelos de desarrollo hacia una agenda de posdesarrollo (Kothari, Demaria \& Acosta, 2014). De hecho, el tema ambiental es controversial y polisémico (Carneiro, 2005; Freire, Bozelli, Espinet \& Martins, 2012; Jatobá, Cidade \& Vargas, 2009; Teodoro, 2012).

Desde el año 2015 contamos con los Objetivos de Desarrollo Sostenible (ODS), que forman parte del Protocolo Internacional de la Asamblea General de las Naciones Unidas (ONU) en donde los países firmantes se comprometieron a implementar la Agenda 2030 para el Desarrollo Sostenible. Estas acciones implican crear conciencia, adquirir conocimiento y movilizar acciones para garantizar más justicia social y preservación del medio ambiente. Sin embargo, muchas de ellas no rechazan el modelo de crecimiento y desarrollo que hemos experimentado hasta hoy y más bien proponen medidas paliativas que se basan en avances tecnológicos para resolver problemas ambientales. Al respecto, para Nascimento (2012), el discurso ambiental oficial y hegemónico 
no es transformador, por lo que este debiera contemplar una inversión en desarrollo tecnológico para superar riesgos y problemas ambientales y planteamientos para que todos los seres humanos puedan acceder en igualdad de condiciones a mejores futuros y a una mayor calidad de vida.

Diferentes discursos hegemónicos (Alves, 2010; Laclau y Mouffe, 2004) frente a temáticas ambientales se orientan por medio de una matriz común que tuvo su origen en la década de 1970 en las grandes conferencias de la Unesco y, si bien fueron cambiando de énfasis, siguen cultivando la "sustentabilidad de mercado" (Lima, 2003). Estos discursos son particularmente potentes en el hecho de involucrar a diversos sectores de la sociedad, asumiendo una dimensión de valor compartido, aunque presentan una factibilidad débil (Lima, 2003), dado que las propuestas de desarrollo que se insertan en una sociedad capitalista se orientan por el mercado (Harvey, 2003).

Así mismo, estos discursos han colonizado diversos campos del saber —entre ellos el educativo (Lima, 2009)— y de estos podemos destacar los siguientes:
a) Agenda 21, lanzada en 1992
(Malheiros, Philippi Jr. \& Coutinho, 2008) y sus incidencias en los currículos escolares.
b) Objetivos del Milenio en los ańos 2000 (Sachs, 2012) y en 2015 los ODS (ver Agenda 2030, Organização das Naçôes Unidades, ONU, 2015).
c) Propuestas a nivel local de temas generadores como, por ejemplo, para 2019 la red de escuelas públicas de Río de Janeiro tuvo como tema el abordaje de los ODS.

Sin embargo, las dimensiones políticas y culturales suelen quedar fuera de la planificación de estas aproximaciones (Nascimento, 2012), ya que reconocer las diferencias entre grupos sociales respecto del acceso a un medio ambiente sano y al poder de decisión frente a los diferentes usos de este y sus valores culturales forman parte de una mirada crítica a la cuestión ambiental.

Así por ejemplo, Freire y Rodrigues (2020) destacan que los "saberes ambientales plurales" y contar con una formación ciudadana son vías para abordajes más radicales a la temática, puesto que ponen el foco en las sociedades patriarcales y extractivistas que consideran al ser humano como el centro de todo y donde todo se puede mercantilizar y consumir (Bauman, 2001). Además, estos saberes proponen un diálogo con la ciencia comprendida como actividad humana que busca descubrir, a través de un mezcla de experimentación y razonamiento teórico, las entidades, estructuras y mecanismos que existen y operan en el mundo (Bhaskar, 1997; Hamlin, 2000). Este diálogo acerca los campos de la educación en ciencias y de la educación ambiental frente a sus objetivos sociales debiera generar mayores posibilidades para que los procesos de enseńanza-aprendizaje referidos a los aspectos tecnocientíficos estén inmersos en las cuestiones sociales, políticas y económicas. Lo anterior permite la comprensión de las materias macrosociales que generan los problemas socioambientales, junto con la participación social a partir de la toma de decisiones no solamente individuales, sino sumamente colectivas (Sauvé, 2010).

Dada entonces esta coyuntura global del tema ambiental y los retos para el siglo XXI y sus alcances pedagógicos, nos interesa investigar la práctica educativa considerando las posibilidades de elaboración teórica a partir de la siguiente pregunta: ¿Cuáles son los límites y posibilidades de la práctica pedagógica escolar al resignificar acuerdos globales para la sostenibilidad a partir de una mirada crítica a tales acuerdos?

Por tanto, el presente estudio interpretó críticamente los ODS para comprender la escala local y global de los problemas socioambientales y sus interrelaciones, a partir de una práctica educativa que caracteriza el tema ambiental como complejo, que dispone de las dimensiones culturales, laborales, políticas y geoepistemológicas (Harvey, 2003), así como de las transformaciones políticas y económicas para comprender el mundo contemporáneo, además de las dimensiones ecológicas. Asumimos el supuesto de que el lenguaje multimodal (Márquez, Izquierdo 
y Espinet, 2003) y diferentes géneros textuales (Borges, 2012) cumplen roles específicos en el aula y favorecen el abordaje de la complejidad de la cuestión ambiental, dando significado a los conocimientos científicos escolares presentes en los temas ambientales y, a la vez, se abren a otras expresiones como el arte con un abordaje sociocultural, lo cual creemos que es fundamental para el desarrollo de una mirada crítica a los ODS en un plan pedagógico.

\section{Marco de referencia}

Como marco teórico desarrollamos aspectos referidos a la sostenibilidad, la educación ambiental y las representaciones que son relevantes para esta investigación.

\section{La sostenibilidad en la sociedad contemporánea y el debate académico del concepto}

Desde un punto de vista histórico, los términos sustentabilidad y sostenibilidad surgen a partir de debates y preocupaciones acerca del medio ambiente y las interferencias humanas. El movimiento ambiental, por su parte, presenta fases distintas donde al inicio del siglo XX, la ecología y la economía eran incompatibles. Según Jatobá et al. (2009), fue en medio de la crisis del petróleo en la década de 1970 cuando surgió el ambientalismo moderado, el cual logró compatibilizar economía y ecología, motivado por la amenaza de la continuidad del modelo económico debido al agotamiento progresivo de los recursos naturales del planeta. Desde ahí, la conciliación pasó a formar parte de los discursos oficiales, primeramente con el ecodesarrollo - término planteado por Ignacy Sachs (1993) y que comprende cinco dimensiones: social, económica, ecológica, cultural y espacial— que ofrecía una visión moderada, pero todavía algo crítica al modelo desarrollista (Kon, 2007) en marcha en los países de Latinoamérica (Trejos, 2012). Posteriormente, para proporcionar una perspectiva más amistosa, el término fue cambiado a desarrollo sustentable — diferentes autores presentan traducciones variadas entre sostenible y sustentable, las que vamos a discutir más adelante- que se definió como aquel que "satisface las necesidades de la generación actual sin comprometer la capacidad de generaciones futuras para satisfacer sus propias necesidades" (ONU, 1987, p. 23). El concepto se encuentra presente actualmente en los discursos oficiales globales y llama la atención sobre los límites de absorción y regeneración de los ecosistemas para el futuro humano.

Respecto de la disparidad de definiciones, Rodríguez y Héctor (2006) investigaron en detalle las distintas concepciones construidas en torno al desarrollo sustentable, pero hicieron hincapié en el término sostenible. $\mathrm{Al}$ respecto, consideran que contrariamente al desarrollo sustentable, el desarrollo sostenible trasciende los intereses económicos para llegar a la comprensión de la necesidad de establecer dispositivos de reapropiación de la naturaleza, que consideren aspectos multidimensionales propios de las distintas identidades colectivas. Además, el término sostenible (en el sentido que estamos utilizando aquí) implica una relación con la naturaleza que es el resultado de arreglos y compromisos sociales, políticos y económicos por parte de los sujetos, tendientes a buscar el equilibrio Estado-mercado-sociedad-medio ambiente (Rodríguez y Héctor, 2006).

De este modo, las disputas ambientales ganan, en determinadas partes de Latinoamérica, palabras propias con sentidos que avalan relaciones más o menos radicales en torno a los cambios socioambientales (López Ricalde, López Hernández y Ancona Peniche, 2005). Complementariamente, el trabajo de López-Pardo (2012) presentó un posible mapa de la transición hacia la sostenibilidad y avanza en consideraciones referidas a la gobernanza global, pero sigue apostando por innovaciones tecnológicas y nuevas estructuras sociales. A eso se suman los términos sostenibilidad débil y fuerte (Álvarez, 2013, Fernández y Gutiérrez, 2013; López-Pardo, 2012). GonzálezGaudiano, Meira-Cartea y Martínez-Fernández (2015), en tanto, recuperaron las críticas frente al término de desarrollo sustentable y a las propuestas de diferenciación de sostenibilidad débil y fuerte, ante la infinidad de debates poco consensuados en el tema. 
En tiempos contemporáneos, valdría la pena reflexionar y discutir cómo una sociedad podría considerarse de hecho sostenible (sostenibilidad fuerte), cuando las políticas económicas capitalistas — que velan por las relaciones internacionales bien remuneradas, la expansión de los industriales, la agricultura, etc. - no permiten una sociedad igualitaria (Hearn, Foth \& Stevenson, 2011; Wade, 2004). Además, el modelo sigue generando alteraciones en el clima (Nobre, Lahsen \& Ometto, 2008), la destrucción masiva de recursos naturales (Vanhulst y Beling, 2013) y otros problemas ambientales. Dicho de otro modo, coincidimos en que, si no se supera el ambientalismo moderado para transitar hacia perspectivas más radicales que permitan concretar una agenda de posdesarrollo (Kothari et al., 2014), los planteamientos acerca de la sostenibilidad tendrán igualmente una baja efectividad. Es por ello que consideramos que desde la década de 1980 la emergencia de discusiones provenientes de la ecología política ha contribuido a que los aspectos culturales de las comunidades locales estén intrínsecamente relacionados con las estructuras sociales y políticas, creando escenarios de ruptura con las disposiciones existentes. Así, con el tiempo han ido ganando fuerza los movimientos ambientales que abogan por justicia social y proponen resistencias y alternativas al desarrollo (Jatobá et al., 2009), así como otras posibilidades para las nuevas emergencias socioambientales y, aunque todavía se asientan teóricamente en el campo de la ecología política, tales discusiones podrían contribuir con el tiempo al fortalecimiento del campo de práctica y de investigación en educación ambiental.

Por otra parte, para Kothari et al., (2014) una agenda de posdesarrollo tiene como características la gobernanza política y la economía "centrada en la comunidad" (p. 370), lo cual implica una democracia directa más representativa y con instituciones de gobierno responsables de las instituciones locales, donde los medios de producción son vistos como propiedad pública o comunitaria y se adoptan políticas públicas para la sostenibilidad sin enfatizar en la competencia del mercado a nivel global. De igual forma, podemos señalar que otra característica de la agenda posdesarrollo es la justicia y la equidad social, donde se respeta la diversidad cultural y las espiritualidades y cuya relación entre el ser humano y la naturaleza contempla también nuevos enfoques basados en el valor de la vida no humana.

En síntesis, los conceptos centrales de la presente discusión tienen relación con situar la sostenibilidad en planes discursivos y vincularlos con los compromisos efectivos para la transformación social. De aquí surge el enlace con abordajes que descubren las tensiones entre hegemonías discursivas respecto de lo ambiental. En el ámbito de los abordajes más radicales, considerando la opción y agenda de posdesarrollo emerge la propuesta de sociedades sostenibles (Diegues, 1992; Leff, 2007; Lima 2009), la cual enfatiza la pluralidad de caminos por construir. De hecho, el equipo de esta investigación ha venido trabajando con las emergencias de "nuevos" caminos (Freire \& Rodrigues, 2020) y lo que hemos encontrado permite caracterizar el Swaraj en India (Kothari, 2018), el Buen vivir con origen en los pueblos ancestrales andinos (Acosta, 2012) y el Ubuntu en África subsahariana (Le Grange, 2018) como perspectivas que no se presentan como cerradas ni buscan ser totalizadoras.

Por último, queremos señalar que el posdesarrollo es un término que no tiene mucho sentido para Latinoamérica, ya que muchos de nuestros países no han logrado aún un "desarrollo" (entendido como control y poder del capital). Aun así, los ejemplos citados se encuentran en regiones que tampoco no han logrado este desarrollo occidental, lo cual es positivo porque quizás para ellos algunos de los retos de los acuerdos globales forman parte de sus rutinas y de sus relaciones con la naturaleza.

Finalmente, sabemos que el debate entorno a estas materias no es sencillo, pues aunque hayamos adoptado el término sostenibilidad suponiendo un vínculo con procesos emancipadores y transformadores de la sociedad, muchos autores señalan la existencia de límites en las propuestas a partir del escenario global presentado en la introducción. 


\section{Educación ambiental en las prácticas educativas}

Situamos nuestro trabajo en el campo de la educación ambiental, pues reconocemos el rol de la investigación en esta materia en Latinoamérica. Así, basada en compromisos con la transformación social, "la educación ambiental tiene como desafíos la concienciación y el despertar de la reflexividad de un ser humano que necesita repensar su relación con el medio ambiente y los valores que lo impregnan” (Marin, 2006, p. 277).

Por su parte, a lo largo de la década del 2000, la educación ambiental en Latinoamérica se ha entendido cada vez más como un campo político (Bourdieu, 2011) donde diferentes agentes sociales evidencian distintas posiciones políticas y operativas. Esto implica comprenderla en su complejidad genealógica, frente a representaciones lineales e historicistas que no ignoran los enfrentamientos, conflictos y luchas que la constituyeron (Meira, 2009) y la abordan desde una doble perspectiva: por un lado, establecen sus límites y la posición relativa que ocupa socialmente y, por otro, apuntan a su estructura interna para interpretar las causas de su vulnerabilidad y subordinación a la dinámica de otras personas, a pesar de los avances realizados en el pasado (Núñez, Castro y Cartea, 2017).

De este modo, las disputas internas y externas que caracterizan aspectos o corrientes de la educación ambiental, asumen carices diferentes y, a veces, antagónicos que le confieren una noción dinámica a su identidad, desvelando las tensiones externas que originan por ejemplo, la aparición de la educación para el desarrollo sustentable, tal como lo plantea González-Gaudiano y Puente (2010), así como también de la educación para la sostenibilidad, que lejos de ser retórica, denuncia una disputa para hegemonizar el campo de la educación ambiental. Para Lima (2009), una sustitución de términos representa además un retroceso político y pedagógico, puesto que echa mano de marcos identitarios marcados por el socioambientalismo crítico y emancipatorio por una nueva denominación que plantea aspectos economistas en los discursos desarrollistas del ambientalismo moderado y las influencias conservadoras del pensamiento contemporáneo de hegemonía neoliberal. En los tiempos actuales (Giddens, 2003) este problema se acentúa, puesto que para muchos autores los discursos tienen una naturaleza híbrida (Fairclough, 1992): si, por un lado, los discursos híbridos son constitutivos de la modernidad tardía, por otro — cuando el compromiso de la educación ambiental es con la transformación social—, no todos sirven a este objetivo.

Ahora bien, desde una mirada regional, en Latinoamérica (González-Gaudiano \& Lorenzetti, 2009) el debate respecto de la práctica pedagógica en educación ambiental muestra contornos más bien borrosos: por un lado, están las propuestas conservacionistas (Layrargues \& Lima, 2014) que centran sus pedagogías en los temas ecológicos del debate ambiental, pragmáticas que apuestan por la gestión efectiva de bienes de consumo desde la producción hasta la eliminación gracias a la tecnología; y por otra, las fórmulas de organización política y social a las que a menudo no responden nuestras jóvenes democracias (Gadea \& Scherer-Warren, 2005).

Por otra parte, si bien la característica interdisciplinaria de la educación ambiental enriquece el campo con discusiones amplias y profundas, el estudio del medio ambiente involucra muchos otros temas que se extienden a través de diferentes materias escolares. Así mismo, pese a que la preocupación ambiental ha ganado espacio en los planes de estudio escolares en todo el mundo (Torales, 2013), esta aún habita un "no lugar" en las políticas públicas, y en los espacios educativos (Freire \& Rodrigues, 2020).

En efecto, a menudo se cifra en los profesores de ciencia la responsabilidad de su enseñanza. Sin embargo, para González-Gaudiano (2005) tratar la dimensión ambiental en el currículo escolar en forma de asignaturas "no solo fragmentaría lo ambiental, como con otras asignaturas, sino que evitaría la articulación con diferentes áreas de conocimiento en busca de crear relaciones interdisciplinarias" (p. 126). En este sentido, según Leff (2002) la fragmentación del conocimiento en las disciplinas estaría directamente relacionada con la alienación de las personas frente a los problemas ambientales, en tanto que Figueiredo (2020), lejos de resolver el debate, identificó la existencia de un enfoque interdisciplinario de educación ambiental en educación superior, por lo que la interdisciplinariedad aparecería como una forma de reestructurar el conocimiento escolar que tradicionalmente ha sido disciplinario. 


\section{El dibujo como vía para evocar y dar sentido a los fenómenos observados}

En el contexto de educación en ciencias donde se impartió el taller, buscamos los aportes teóricos de este campo y sus relaciones con las representaciones. Ello, porque poder explicar el mundo que nos rodea desde las ciencias naturales significa relacionar hechos y entidades teóricas imaginadas, de modo que el discurso generado sea significativo (Merino \& Sanmartí, 2008). La evolución de las explicaciones a lo largo de la historia de la ciencia ha implicado revisar "las formas de mirar" los hechos, así como imaginar entidades teóricas y hablar de ellas. Del mismo modo, hacer ciencia en la escuela implicaría ayudar a nuestros estudiantes a generar entidades imaginarias y usarlas de manera significativa para explicar sus observaciones, en nuestro caso con los ODS. De este modo, el aprendizaje a lo largo de la escolaridad estaría relacionado con estimular a los niños y niñas a probar sus modelos iniciales por medio de la realización de nuevos experimentos e imaginando cambios en sus modelos para que sean más coherentes y cuenten con mejores formas de hablar acerca de ellos (Scott \& Jewitt, 2003).

En la escuela, estas entidades no son necesariamente las de la ciencia experta, pero deben ser coherentes con ella de una forma u otra, de modo que puedan evolucionar a través de la escolarización, esto es, que las entidades en la ciencias escolares deben ser resonantes de la ciencia erudita (Acher, Arcá \& Sanmartí, 2007). Desde esta perspectiva aprender, entonces, implica cambiar el significado de las experiencias; por lo tanto, si alentamos a nuestros estudiantes a desarrollar estrategias que los ayuden a imaginar modelos, comunicarlos, probarlos y regularlos, podemos afirmar que están realizando una actividad científica escolar (Izquierdo \& Adúriz-Bravo, 2003).

$\mathrm{Al}$ respecto, cuando hablamos de "modelos", queremos decir que, como otros conceptos metacientíficos, estas nociones desafían la definición formal (Ziman, 2001). Por ejemplo, un punto de vista aceptado hoy en día afirma que un modelo "es una representación de una idea, objeto, evento, proceso o sistema, creado con un objetivo específico” (Justi, 2006). De alguna manera, esta representación abstrae y traduce la entidad modelada no solo a partir de percepciones directas, sino también de ideas anteriores. En el contexto de la actividad científica, imaginar implica modelar. El proceso de modelado también involucra cambiar las formas de hablar acerca de los fenómenos y del modelo generado. Así, inicialmente, las palabras o los dibujos utilizados para describir un fenómeno o alguna interpretación provienen del lenguaje cotidiano y de analogías relacionadas con situaciones o explicaciones que ya se conocen (Selley, 2000). A través del proceso de modelado, los estudiantes reconocen la necesidad de generar nuevas representaciones y usar nuevas palabras - o en nuestro caso, dibujos - que expresen mejor el modelo que da sentido a los fenómenos observados. Este nuevo significado de cualquier representación sería tipo "visualización", lo que es muy importante en ciencias y más aún para la educación científica, donde se requiere que los estudiantes adquieran esta capacidad de transitar progresivamente entre niveles de representaciones (macro, micro y simbólica), como también en subniveles (3D, 2D, 1D) y logren moverse entre ellas (Gilbert, 2005). Si bien por ahora los estudios referidos a la visualización profundizan en las representaciones en química y no utilizan la terminología adoptada en este artículo, la idea de progresión en la competencia representativa de Kozma y Russell (2005) es útil, ya que sugiere qué oportunidades educativas se deben proporcionar para poder desarrollar la visualización. Sin embargo, esta progresión necesita ser reformulada en términos de "niveles de representación”, los que son específicos para cada noción científica, en nuestro caso los ODS (ONU, 2015). 


\section{Metodología}

Para poner en acción las ideas hasta aquí discutidas e indagar en las limitaciones, posibilidades, condicionantes y sustratos cualitativos que ofrece la práctica escolar para resignificar los ODS, nos situamos desde un enfoque metodológico de tipo cualitativo y que constituye un estudio de caso. Este enfoque permite investigar un fenómeno en su contexto real (Yin, 2003), al mismo tiempo que profundiza en el conocimiento de los ODS y sus límites a través de un estudio intensivo de un grupo de estudiantes (Taylor y Bodgan, 1994).

\section{Contexto escolar y participantes}

Los participantes pertenecen a escuelas municipales que se encuentran bajo la estructura de la Consejería Municipal de Educación de Río de Janeiro y se ubican en el barrio de Olaria, en el suburbio de la ciudad. Las escuelas presentan características urbanas, en una zona en la que la densidad demográfica es mayor que 30.000 habitantes $/ \mathrm{km}^{2}$. Los estudiantes pertenecen a estratos económicos bajos y medio bajos. Las características generales de cada escuela son las siguientes:

- La Escuela 1 cuenta con jornada parcial (mañana y tarde) y recibe a estudiantes de $1^{\circ}$ al $9^{\circ}$ año. De esta escuela participaron en el taller 47 estudiantes, los cuales se repartieron en tres sesiones. Los estudiantes (niños y nińas) tenían entre 11 y 15 años de edad.

- La Escuela 2 correspondió a un establecimiento de jornada escolar completa, y donde la música es central en su plan de desarrollo institucional, lo que permite a los estudiantes perfeccionarse en el ámbito de las artes musicales. Esta escuela recibe a estudiantes de $7^{\circ}$ al $9^{\circ}$ ańo y en el taller participaron 57 alumnos (niños y niñas), distribuidos en tres sesiones y que tenían entre 12 y 15 años de edad.

En ambas escuelas el eje temático de 2019 estuvo relacionado con los ODS y, en el caso de la Escuela 2, se trabajó en colaboración con el programa de formación de profesores de la Universidad Federal de Río de Janeiro.

\section{Descripción del taller}

El taller fue organizado y adaptado a partir de lo propuesto por Figueiroa, Andrade, Mejía-Cáceres, Pedroso y Freire (2019), en tres momentos con diferentes modos semióticos, privilegiando las interacciones entre los estudiantes. Los propósitos que orientaron el diseño del taller fueron los siguientes:

- Reconocer diferentes dimensiones de sostenibilidad.

- Analizar datos e imágenes referentes a problemas socioambientales locales o globales.

- Relacionar contenidos discutidos con los ods.

- Reflexionar acerca del rol ciudadano desde las vivencias y las localidades de los estudiantes.

Como contenidos conceptuales trabajamos términos como medio ambiente y sostenibilidad. Los contenidos procedimentales considerados fueron entre otros: analizar y relacionar ODS con los textos e imágenes presentados; discutir y presentar las tareas en grupo y dibujar la visión personal elaborada a partir de las discusiones. Como contenidos actitudinales estimulamos la sostenibilidad como valor social, oír, el trabajo en grupo y sentirse parte de las cuestiones socioambientales, en tanto que como objetivo de aprendizaje se esperaba que al final del taller los estudiantes conocieran los ODS, vinculándolos con una visión más compleja de sostenibilidad en la cual se percibieran como agentes de cambio socioambiental. 
El modelo didáctico utilizado se inspiró en los planeamientos de la ecopedagogía (Payne, 2018) y de la formación en educación ambiental (Cosenza, Freire, Martins \& Espinet, 2014) en los cuales las actividades progresan en etapas de diagnóstico, acción educativa y diálogo generativo, lo cual complementamos con metodologías participativas de discusiones en grupo y técnicas de visualización compartida, y con dibujos en torno a los ODS.

El taller comenzaba con una breve presentación de los relatores para luego pedirles a los estudiantes que formaran cinco grupos de trabajo y así explicarles que cada grupo recibiría un kit con: a) una fotografía de Río de Janeiro; b) una ilustración de una obra de arte; y c) un texto de una noticia. La consigna fue que tendrían que discutir y descubrir respecto de la pregunta: ¿qué tienen en común estos tres objetos? (Ver anexo 1).

Todos los grupos contaron con la presencia de un mediador del grupo de investigación que dirigió la discusión a través de preguntas clave previamente seleccionadas, las que provocaron la reflexión en torno a los problemas socioambientales que actualmente experimentamos: ¿Qué observan? ¿Cómo se relacionan los elementos que componen los materiales? ¿Qué crees que significa esta imagen? ¿Hay algo en común entre la fotografía, las ilustraciones y los informes? ¿Estos materiales tienen algo que ver con el medio ambiente?

Después de la discusión en los grupos, uno o más representantes exponían brevemente para todos en la sala las reflexiones planteadas en el análisis de los materiales. Al final de las presentaciones, cada grupo señalaba en cuáles de los ODS era posible localizar los temas debatidos. A continuación, se producía el momento de la discusión colectiva en torno al concepto de sostenibilidad y los ODS, para proceder a explicar las conexiones entre los materiales presentados buscando contrastes, derechos y accesos a las propuestas de los ODS. Luego de la explicitación y de la relación de los ODS se plantearon las siguientes preguntas: ¿Cuáles fueron las discusiones planteadas por su grupo? ¿Qué tiene que ver todo esto con el medio ambiente? ¿Qué significa sostenibilidad? ¿Cómo podemos interpretar la sostenibilidad como valor social (actual) en el material analizado? ¿Qué aspectos de los ODS pueden representarse en el material?

Finalmente, los estudiantes debían dibujar o escribir en una hoja en blanco algo que, para ellos, era importante para garantizar un mundo más sostenible en función de la discusión realizada a partir de las preguntas evocadoras respecto de los ODS.

\section{Estrategias para el análisis de los datos}

Para comprender los datos generados en el taller, en términos de limitaciones, posibilidades, condicionantes y sustratos cualitativos para la significación de los ODS, recurrimos mayoritariamente a los dibujos elaborados por los participantes en el taller. En función de estos insumos establecimos una estrategia de tres etapas progresivas:

Clasificación de los componentes principales de los dibujos. La fase inicia con la búsqueda de regularidades, posibilidades y limitaciones. Entre las distintas propuestas metodológicas para organizar y analizar datos cualitativos obtenidos a partir de instrumentos abiertos, entrevistas, observaciones en el aula, dibujos, entre otros registros, podemos emplear "redes sistémicas". Al respecto, para Bliss, Monk y Ogborn (1983) — proponentes de esta metodología-, las redes que resultan de la revisión de dibujos, mostrarían la dependencia e independencia entre las ideas, sentimientos y valores, los que en nuestro caso expresaron los estudiantes participantes del taller. Ahora bien, cada configuración es solo una de las muchas posibles que pueden ocurrir y que deben ser interpretadas por el investigador, quien las estructura a partir de lo que se dice, de lo que está escrito o dibujado, en nuestro caso. Para generar ese enlace entre lo dicho, lo escrito y lo dibujado en la red sistémica Bliss et al. (1983) proponen reglas que permiten establecer un lenguaje gráfico común entre los individuos que utilizan esta metodología. Los criterios y resultados que se obtienen una vez que se ha verificado el proceso pueden (o no) satisfacer a los lingüistas o a los científicos, pero permiten conectar la descripción de los datos con las posibles características (o interpretaciones) de estos. 
En general, se inicia la construcción de una red sistémica cuando se "leen" los dibujos que se quieren organizar. Así, el primer paso fue la organización, clasificación y codificación de los dibujos (Figura 1), para luego contabilizar la frecuencia porcentual de eventos (Figura 2).

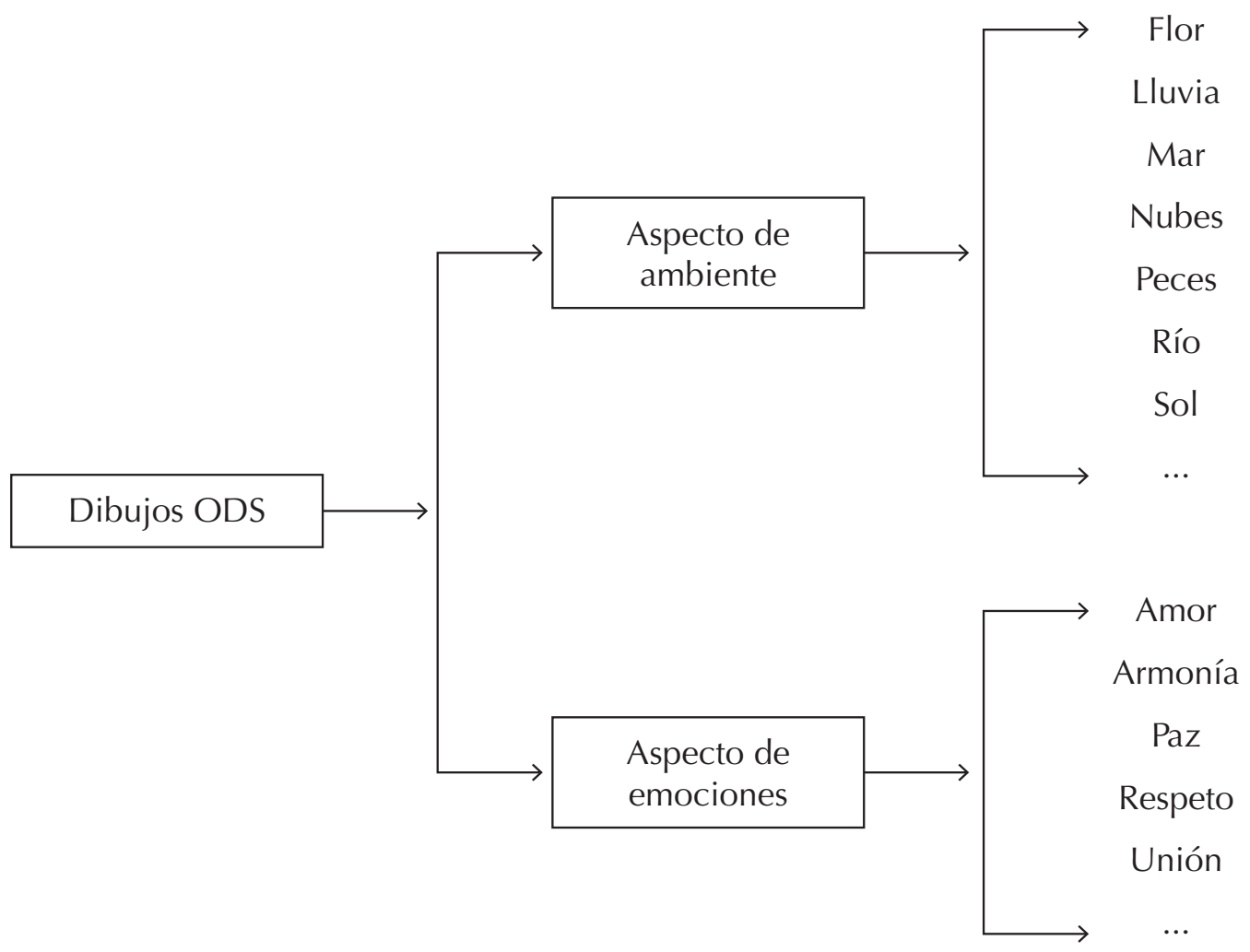

Figura 1. Red sistémica con componentes principales de los dibujos recogidos en el taller.

Fuente: Elaboración propia.

Identificación de los dibujos con un ODS. La segunda fase continúa de forma complementaria a la clasificación de los dibujos, con una asignación temática a uno de los 17 ODS. Una vez codificados los dibujos e identificados sus componentes principales a través de las redes, se procedió a vincularlos con las temáticas que se establecen en los ODS. Esta asignación fue realizada por dos investigadores expertos y se empleó un estadístico de índice de kappa de Cohen para evaluar la subjetividad en la clasificación de los dibujos.

Niveles de representación de los ODS. Finalmente, la tercera etapa de esta estrategia se completa con la asignación de niveles de representación (Kozma \& Russell, 2005). Tal como indicamos previamente, estos niveles necesitan ser reformulados para que sean específicos a los objetivos y metas de desarrollo sostenible (ONU, 2015). La Tabla 1 presenta los niveles y su traducción en clave de los ODS y lo esperado para cada nivel, teniendo claridad que esto en rigor es una primera aproximación metodológica. 
Tabla 1

Niveles de representación vinculados a los $O D S$

Código Niveles $\quad$ Descripción

\begin{tabular}{|c|c|c|}
\hline Nivel 1 & $\begin{array}{l}\text { Representación como } \\
\text { descripción }\end{array}$ & $\begin{array}{l}\text { Cuando se le pide que represente el mundo sostenible, la persona } \\
\text { genera representaciones basándose en símbolos ya representados } \\
\text { en los ODS o en las obras de arte del kit; utiliza imágenes de } \\
\text { sentido común y/o genéricas. }\end{array}$ \\
\hline Nivel 2 & $\begin{array}{l}\text { Habilidades simbólicas } \\
\text { tempranas }\end{array}$ & $\begin{array}{l}\text { Cuando se le pide que represente el mundo sostenible, la persona } \\
\text { genera representaciones en función de uno de los aspectos } \\
\text { de la sostenibilidad (ecológicos, económicos, otros), pero } \\
\text { también incluye algunos elementos simbólicos para acomodar } \\
\text { las limitaciones del medio (por ejemplo, el uso de elementos } \\
\text { simbólicos como flechas para representar nociones dinámicas, } \\
\text { tiempo, movimiento o una causa observable, en un medio estático } \\
\text { como el papel) creando sus propias representaciones. }\end{array}$ \\
\hline Nivel 3 & $\begin{array}{l}\text { Uso sintáctico de } \\
\text { representaciones formales }\end{array}$ & $\begin{array}{l}\text { Cuando se le pide que represente el mundo sostenible, la persona } \\
\text { genera representaciones en función del enlace entre dos o más } \\
\text { dimensiones de la sostenibilidad, exhibiendo un proceso o } \\
\text { comportamiento frente al medio (aunque no sean procesos } \\
\text { precisos, están orientados hacia transformación de la sociedad), } \\
\text { por medio de símbolos y creando sus propias representaciones. }\end{array}$ \\
\hline Nivel 4 & $\begin{array}{l}\text { Uso semántico de } \\
\text { representaciones formales }\end{array}$ & $\begin{array}{l}\text { Cuando se le pide que represente el mundo sostenible, la persona } \\
\text { usa un sistema de símbolos formales para representar entidades y } \\
\text { procesos subyacentes, observables o no, que expresan diferentes } \\
\text { dimensiones de la sostenibilidad, además de incluir relaciones } \\
\text { temporales entre pasado, presente y futuro y de causa efecto. La } \\
\text { persona puede hacer conexiones a través de dos representaciones } \\
\text { diferentes, o bien, transformar una representación en otra } \\
\text { en función del significado compartido de las diferentes } \\
\text { representaciones y sus características. }\end{array}$ \\
\hline Nivel 5 & $\begin{array}{l}\text { Uso reflexivo y retórico } \\
\text { de las representaciones }\end{array}$ & $\begin{array}{l}\text { Cuando se le pide que represente el mundo sostenible, la persona } \\
\text { usa una o más representaciones para explicar la relación entre } \\
\text { diferentes dimensiones de la sostenibilidad, incluyendo relaciones } \\
\text { temporales entre pasado, presente y futuro y de causa y efecto, } \\
\text { dentro de un contexto social donde la persona es partícipe del } \\
\text { cambio/transformación social. }\end{array}$ \\
\hline
\end{tabular}

Fuente: Elaboración propia sobre la base de Kozma y Russell (2005).

Para validar la matriz y consignación de los dibujos con un nivel y con un ODS, utilizamos el test de índice de kappa (índice de concordancia) entre dos expertos de educación ambiental. Como indicador de reproducibilidad esto tiene el inconveniente de que aún si los dos observadores clasifican con criterios independientes, eventualmente, se podría producir un cierto grado de acuerdo por azar. Es deseable que un índice de concordancia tenga en cuenta este hecho y que, de algún modo, indique el grado de acuerdo que existe por encima del esperado por azar. En este sentido, el índice más usado es el propuesto por Cohen (ecuación 1) denominado índice kappa ( $k$ ) que se define como:

$$
K=\frac{P_{0}-P_{\mathrm{C}}}{1-P_{\mathrm{C}}} \quad(\text { ecuación } 1)
$$


Siendo $\mathrm{P}_{0}$ la proporción de acuerdos observados y $\mathrm{P}_{\mathrm{c}}$ la proporción de acuerdos esperados en la hipótesis de independencia entre los observadores, es decir, de acuerdos por azar. En nuestro caso, el grado de acuerdo en la clasificación de los dibujos fue de 0,86 según el valor $k$ para el caso de la clasificación de los dibujos. Según Cerda y Villarroel (2008) para valores obtenidos en el rango [0,61-0,80], el grado de acuerdo es considerado sustancial.

\section{Resultados y discusión}

Esta etapa se estructuró en dos secciones. La primera ofrece una descripción más general respecto de las discusiones ocurridas durante los talleres y las posibilidades vivenciadas para superar el discurso ambiental oficial y hegemónico, añadiendo las dimensiones culturales y de poder. La segunda etapa, más específica, presenta los significados de los dibujos y los niveles de representación frente a lo ambiental, los que han transitado entre propuestas de sostenibilidad que reproducen hegemonías y las que están orientadas hacia la transformación social.

\section{Discusiones impartidas durante los talleres. Sustratos cualitativos para la significación de}

\section{los dibujos}

Uno o más representantes de cada grupo presentaron las noticias, la obra de arte y la fotografía (Anexo 1) y, luego, informaron oralmente sus observaciones específicas, a menudo relacionadas con su propia vida diaria, para posteriormente ampliar las relaciones hacia los ODS o la falta de ellos en sus vidas.

Los estudiantes que se quedaron con el kit 1, destacaron la expresión de las personas, el ambiente seco en el fondo y un niño enfermo. Informaron la diferencia en la estructura de las casas de una misma región de la ciudad (algunas lujosas y otras precarias). La falta de saneamiento básico como el punto en común con los tres materiales y cómo esta negligencia puede causar varias enfermedades y estar relacionada con la ausencia de empoderamiento por parte de una comunidad. Así, el rol de los diferentes géneros textuales cumple la función de agregar que la enfermedad tiene determinantes sociales y no es una condición netamente biológica (Buss $\&$ Pellegrini-Filho, 2007). Los contenidos del kit proporcionaron relaciones más explícitas con los ODS 1, 2, 3 y 6.

Por su parte, algunos de los grupos que analizaron el kit 2 destacaron los colores vivos, las expresiones sin vida y cansadas de los posibles trabajadores y la industria como el lugar de trabajo. Resaltaron la contaminación en la que se encuentra la Baía de Guanabara (BG) y se sorprendieron por la cantidad de desempleados en Brasil. Relacionaron todos los materiales con malas condiciones de trabajo y desempleo. Los contenidos del kit proporcionaron relaciones más explícitas con los ODS 7, 8 y 10.

Los estudiantes que analizaron el kit 3 consignaron la destrucción del planeta y del ser humano en el arte. Relacionaron el aumento de las enfermedades con la contaminación, el descuido de las autoridades con una salud de calidad y también con enfermedades causadas por la falta de saneamiento básico. De igual modo, vincularon los tres materiales con el aumento de la contaminación atmosférica, acústica, visual y del agua, el descuido de las autoridades con la población, el aumento de la temperatura, enfermedades y contaminación. En este caso, los contenidos del kit proporcionaron relaciones más explícitas con los ODS 3, 6, 13, 11, 14 y 15. Por último, pese a las posibilidades de relación de la fotografía del Hospital Universitario que se encuentra dentro del Campus de la UFRJ, los estudiantes no mencionaron el ODS 4. 
Para el caso de los estudiantes que interpretaron el kit 4, estos señalaron la expresión de los personajes, la delgadez, la tierra seca y sin oportunidades en la obra de arte. Hablaron acerca de la desigualdad económica y alimentaria en Brasil. Observaron la cantidad de basura en un río y muchos relacionaron los tres materiales con territorios que tienen problemas de miseria, hambre y acceso desigual a mejores condiciones de vida. Los contenidos del kit permitieron establecer relaciones más explícitas con los ODS 1, 2, 10, 12 y 14.

Finalmente, los grupos que tuvieron acceso al kit 5 pudieron observar en la fotografía manifestaciones de la gente protestando por sus derechos; plantearon problemas sociales y políticos. Relacionaron las guerras y sus consecuencias negativas como muertes, sufrimiento y la ausencia de intereses colectivos. Relacionaron los tres materiales con temas como la guerra, la necesidad de una paz mundial efectiva, los derechos sociales y políticos atendidos por el gobierno público y la acción de la ONU en casos extremos. Estos contenidos del kit facilitaron las relaciones más explícitas con los ODS 9, 10, 16 y 17.

En relación con las discusiones producidas, estas generaron un abordaje de las cuestiones ambientales que se acerca a los objetivos planteados para tratar la complejidad socioambiental, procurando crear estrategias didácticas para el tema. De hecho, ante las preguntas y los debates realizados los estudiantes formularon explicaciones respecto de sus visiones de la cuestión ambiental, muchas de las cuales reprodujeron los planteamientos oficiales del ambientalismo moderado. La preocupación por las generaciones futuras fue tema de debate y también el sentido más ecológico de la sustentabilidad. Las figuras, más que los textos, brindaron a la discusión la posibilidad de identificarse con la realidad de los espacios urbanos y algunos estudiantes que miraron la imagen del río informaron que también había un río cerca de su casa, donde sus padres solían bañarse y que ahora está completamente contaminado; otros, al analizar la obra de arte de Pablo Picasso relacionaron la "guerra" con sus experiencias diarias con los disparos en las comunidades aledańas, característicos de las realidades de violencia, inseguridad y conflictos sociales en la ciudad de Río de Janeiro. Esto proporcionó un intercambio de experiencias locales que posibilitó las relaciones con lo global, por medio de experiencias del pasado o del presente. ¿Y el futuro? De algún modo este estuvo representado en los dibujos a partir de lo que los estudiantes consideraron importante para garantizar un mundo más sostenible.

\section{Entre reproducción y transformación social: los significados de los dibujos y los niveles de} representación frente a lo ambiental

En una segunda etapa de análisis del proceso caracterizamos los dibujos a partir de los pasos de la metodología descrita. Primeramente, presentamos los componentes principales de los dibujos, luego su identificación con un ODS y, finalmente, la clasificación de los niveles de representación que evocó la posibilidad de construcción de nuevos planteamientos de un mundo sostenible y superando pedagógicamente sus límites, posibilidades, condicionantes, sustratos cualitativos.

Etapa 1: Clasificación de los componentes principales de los dibujos. En la Figura 2 podemos observar los contenidos iconográficos presentes en los dibujos de las dos escuelas. Los dos grupos de dibujos analizados presentan una proporción expresiva de elementos del entorno y ambiente: bosque, ríos, mar, peces y elementos como el planeta Tierra, agua, así como también aspectos emocionales: alegría, paz y unión con los otros. Es posible observar que en el conjunto de dibujos de la Escuela 1 figuran algunos elementos que no fueron encontrados en los dibujos de la Escuela 2, entre ellos, personas trabajando en actividades tradicionales como pesca y representaciones de gobierno. En la Escuela 2, también hubo elementos diferenciadores, como flores y lluvia. En ambos establecimientos se observaron representaciones de emociones, sin embargo, en la Escuela 1 preponderaron las representaciones de armonía, paz, unión y salud. No fue posible en esta etapa observar una única tendencia en los dibujos, sino solamente contenidos iconográficos que cargan sentidos ecológicos 
u otros, justamente por el hecho de que las emociones estaban presentes, así como los oficios, lo urbano y las instituciones. Sin embargo, en la Escuela 1, el sol fue lo más representado con una presencia del 30\%. En la Escuela 2 el sol fue el segundo aspecto más representado (26\%), como también el bosque (ver Figura 2). Estos resultados coinciden con trabajos que interpretaron dibujos con representaciones del entorno de estudiantes. Por ejemplo, Profice, Pinheiro, Fandi y Gomes (2013) encontraron en su estudio representaciones de bosque con árboles y flores en la mayoría de los dibujos de medio ambiente realizados por estudiantes. En cuanto a las limitaciones, dichos resultados coinciden con Martinho y Talamoni (2007), en cuanto a que la mayoría de los dibujos analizados representan bosques, ríos, animales y plantas, ofreciendo una visión naturalista del entorno influenciado por la religión, la familia, los medios y los materiales didácticos. Como condicionante, observamos resultados similares a Elisei (2008), con una baja inclusión de personas en los dibujos que representan el medio ambiente, lo que indica la posibilidad de una influencia antropocéntrica donde la humanidad se disocia de la naturaleza. En cuanto a las posibilidades, Pedrini, Costa y Ghilardi (2010) marcan la presencia del sol y nubes como representativos de los dibujos del medio ambiente, que sería una línea de trabajo para continuar con el taller a partir de las imágenes seleccionadas para evocar la reflexión con los niños y niñas en las escuelas.

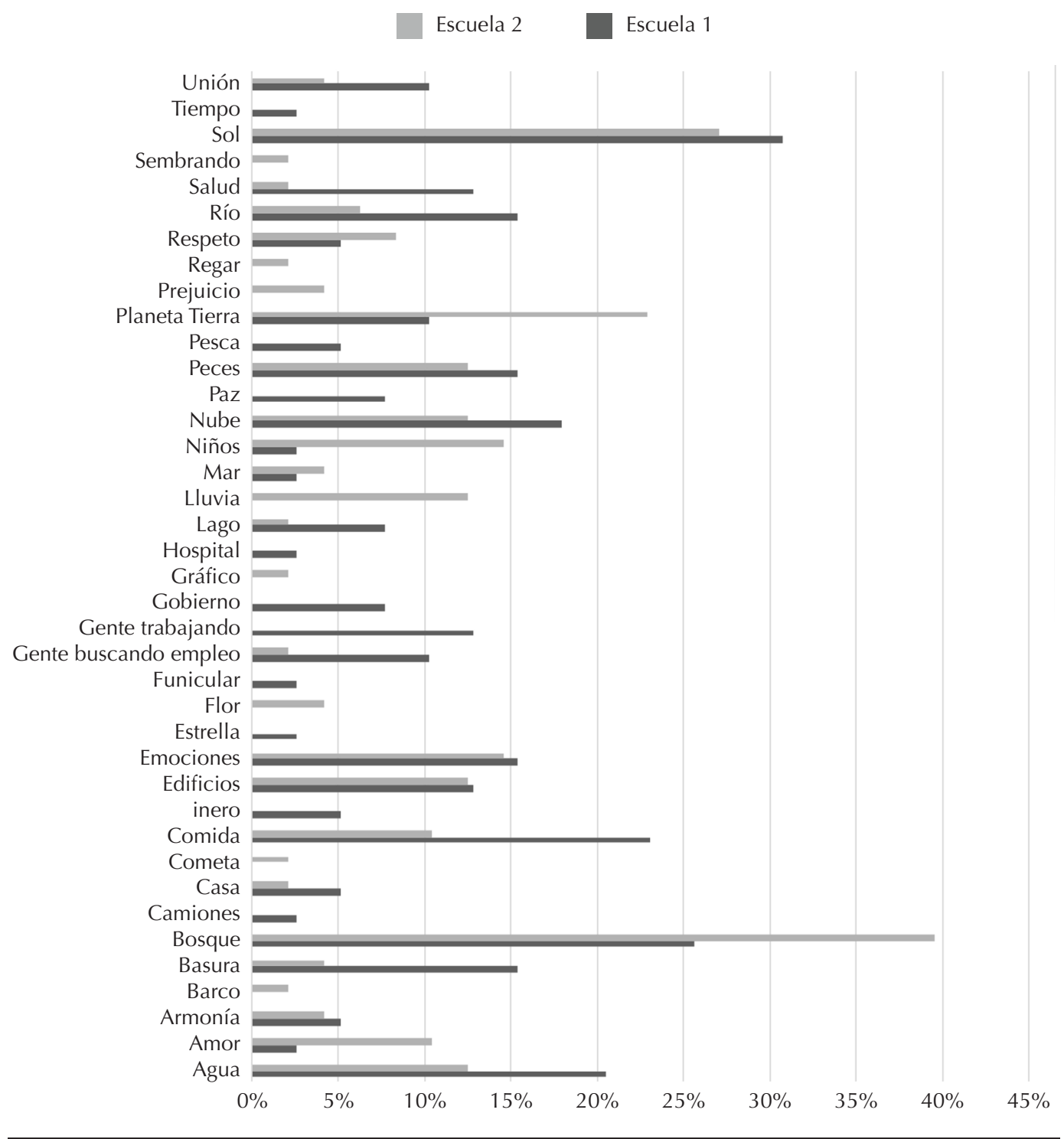

Figura 2. Contenido iconográfico de los dibujos de los niños.

Fuente: Elaboración propia. 
Etapa 2: Identificación de los dibujos con un ODS. En la Figura 3 se observa una comparación entre la caracterización de los 17 ODS representados en las Escuelas 1 y 2. En ambos establecimientos, los ODS identificados con mayor frecuencia fueron: Vida submarina (14), y Vida de ecosistemas (15), los cuales guardan relación con las fotografías proporcionadas (ver Anexo 1). En cuanto a limitaciones, podemos observar que los ODS 4, 9 y 10 no fueron identificados en ninguno de los dibujos analizados. Por su parte, los ODS Hambre cero (2) y Alianzas para lograr los objetivos (17) fueron identificados solo en los dibujos de la Escuela 1, en tanto que los ODS Fin de la pobreza (1) e Igualdad de género (5) se identificaron minoritariamente en los dibujos de la Escuela 2. La frecuencia de identificación entre las escuelas fue similar respecto de los ODS 3, 11, 12, 14, mientras que los ODS 8, 13, 15 y 16, presentaron diferencias entre los más representados. En Escuela 1, la frecuencia del ODS Trabajo decente y crecimiento económico (8) fue proporcionalmente tres veces mayor en la Escuela 1 en comparación con la Escuela 2, y el ODS Paz, justicia e instituciones fuertes (16) fue dos veces mayor que en la Escuela 2. En este mismo establecimiento la frecuencia de identificación del ODS Acción climática (13) fue proporcionalmente cuatro veces mayor que en la Escuela 1, y del ODS Vida de ecosistemas terrestres (15), fue proporcionalmente cuatro veces mayor que en la Escuela 1 (ver Figura 3).

Estos antecedentes permiten observar cierta preponderancia de los ODS en los dibujos de los niños que se sitúan, por un lado, desde los insumos proporcionados y, por otra, a partir de su visión local de los problemas socioambientales y sus interrelaciones. Respecto de los ODS que no fueron identificados ello puede deberse a su abstracción o la falta de énfasis en los materiales presentados para la reflexión. Además, está el hecho de que en la práctica educativa que caracteriza el tema ambiental se sitúa frecuentemente desde los ODS 13, 14 y 15, dejando fuera temas más complejos que disponen dimensiones culturales, laborales, políticas y geoepistemológicas (Harvey, 2003).

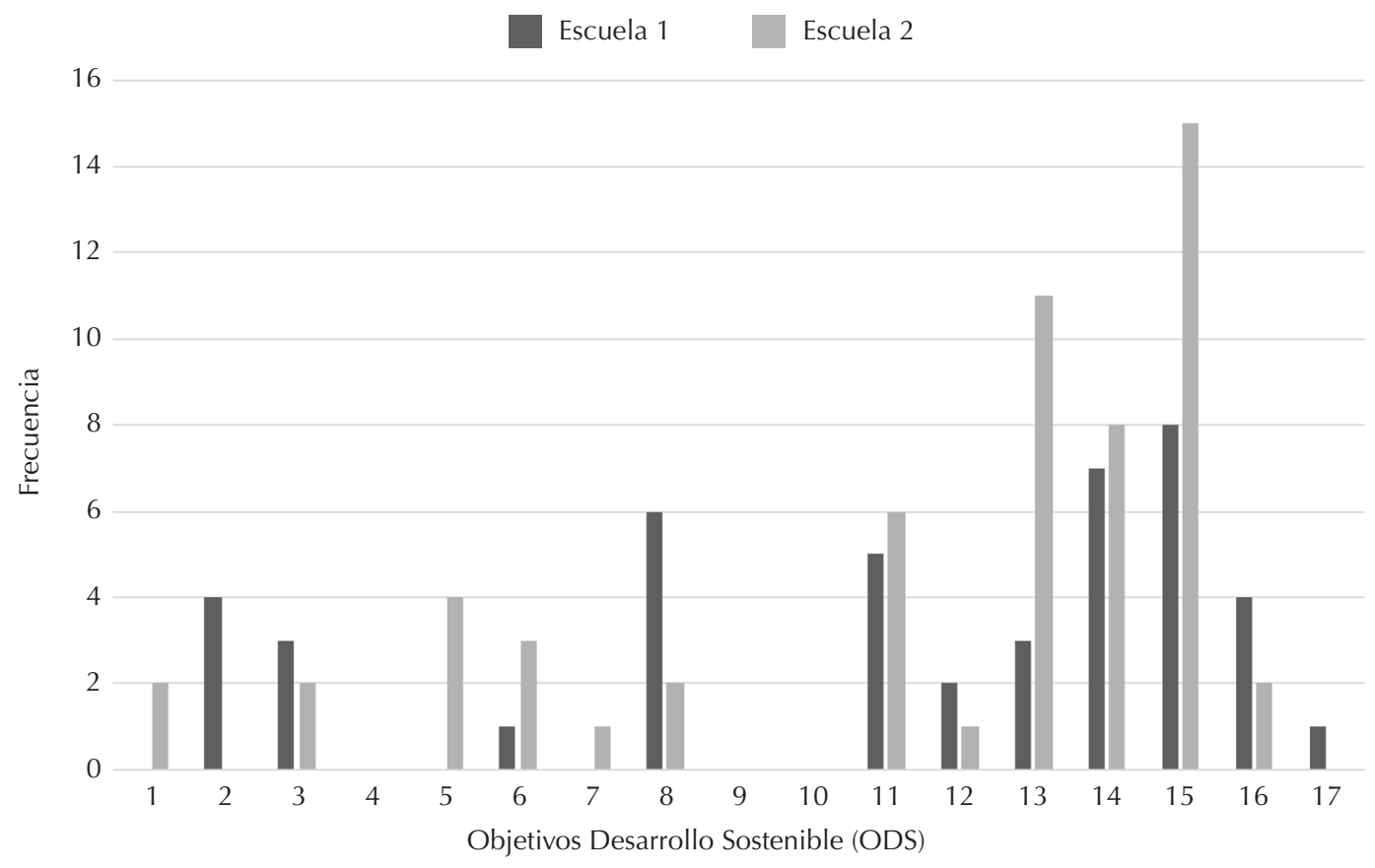

Figura 3. Identificación de los ODS en los dibujos.

Fuente: Elaboración propia. 
Etapa 3: Niveles de representación de los ODS. La Figura 4 muestra los niveles de representación de los ODS identificados en los dibujos de las Escuelas 1 y 2. El 64\% de los dibujos del primer establecimiento y el $52 \%$ de los dibujos del segundo se clasificaron como de nivel 1. Cuando en el taller se les pidió a los niños y niñas que simbolizaran el mundo sostenible, sus dibujos fueron representaciones que se limitaron principalmente a símbolos ya expresados en los ODS, o bien, en las obras de arte del kit, que correspondían a imágenes de sentido común y/o genéricas como árboles, peces, sol, nubes y pájaros.

Por otra parte, el 23\% de los dibujos de la Escuela 1 y el 31\% de los dibujos de la Escuela 2 se clasificaron en el nivel 2, en el cual se considera más la dimensión de sostenibilidad (ecológicos, económicos, u otros), pero también incluye algunos elementos simbólicos para acomodar las limitaciones del medio (por ejemplo, el uso de elementos simbólicos como flechas para representar nociones dinámicas, tiempo, movimiento o una causa observable, en un medio estático como es el caso del papel), creando sus propias representaciones.

De igual modo en ambas escuelas, aproximadamente el 10\% de los dibujos se clasificó con un nivel de sofisticación 3, esto es, que en los dibujos de niños y niñas se observan representaciones en función del enlace entre dos o más dimensiones de la sostenibilidad, presentando un proceso o comportamiento frente al medio (aunque no sean procesos precisos, pero orientados hacia transformación de la sociedad) a través de símbolos y creando también sus propias representaciones.

En la Escuela 2, se observó una leve preponderancia de dibujos más robustos y sofisticados clasificados como de nivel 4 (8\%) respecto de la Escuela 1 (3\%). En estos dibujos fue posible identificar efectos del tiempo, los procesos y las relaciones de causa y efecto, así como también símbolos para representar a las instituciones gubernamentales. En ambas escuelas, los dibujos elaborados por los estudiantes no relevaron sofisticaciones de nivel 5, donde se esperaría encontrar una o más representaciones para explicar la relación entre diferentes dimensiones de la sostenibilidad, incluyendo relaciones temporales entre pasado, presente y futuro o de causa y efecto dentro de un contexto social en el que la persona es partícipe del cambio/transformación social.

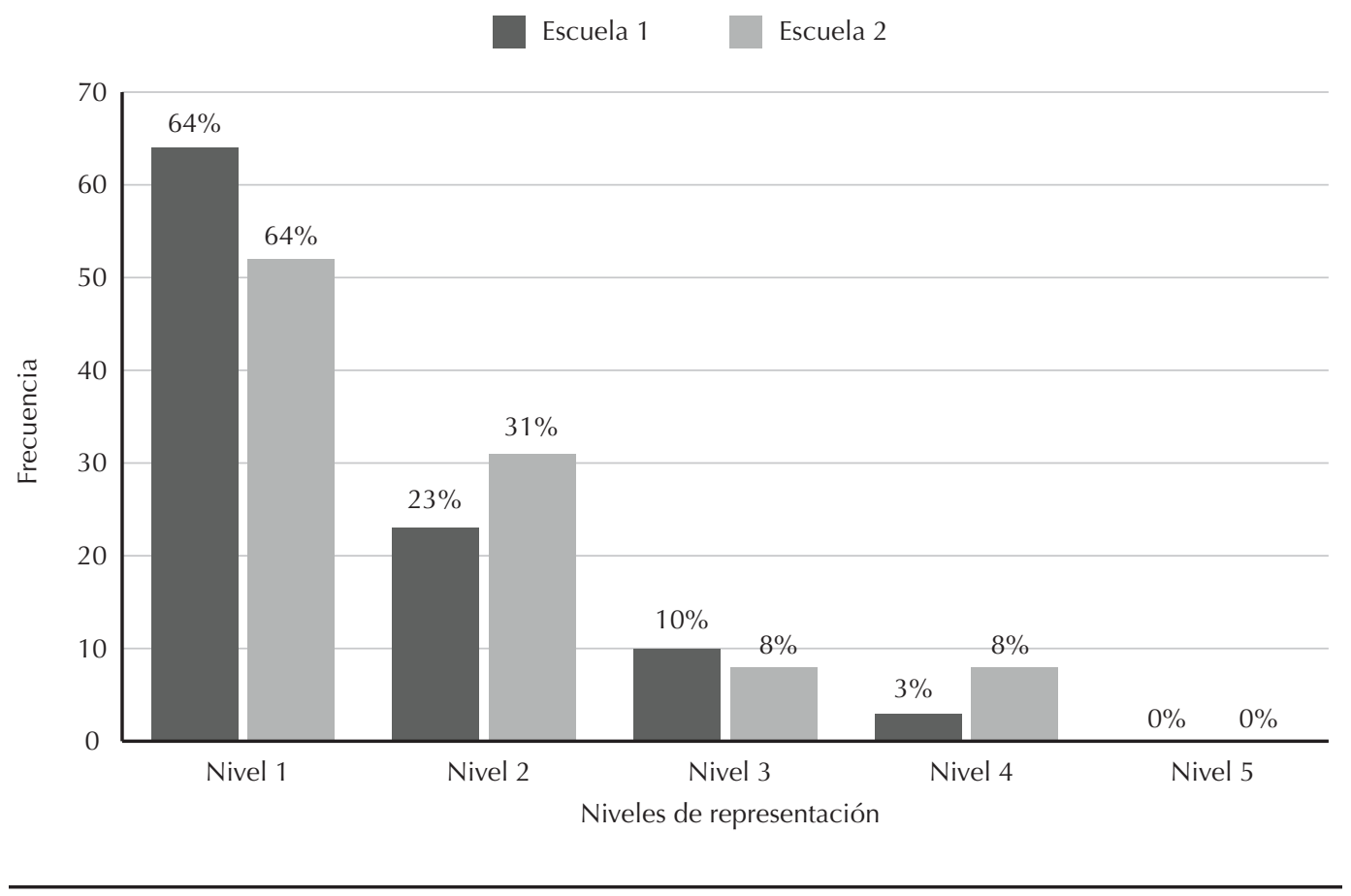

Figura 4. Representación en los dibujos de los niños y niñas respecto de los ODS. Fuente: Elaboración propia. 
La observación de la Figura 4 permite inferir que no todos los estudiantes presentaron niveles elaborados de representación para mostrar las habilidades semánticas para crear sus propias representaciones, o bien, caracterizar una comprensión integrada de los ODS. Tal comprensión precisa reconocer los límites de la propuesta global. Merino y García (2019), quienes analizaron las representaciones de estudiantes utilizando el marco de Kozma y Rusell (2005), observaron esta misma dificultad para profundizar en los niveles de sofisticación y complejidad de las representaciones.

Tabla 2

Ejemplos de dibujos analizados en cada nivel de representación de los ODS

Dibujo clasificado en el nivel 1

Dibujo clasificado en el nivel 2

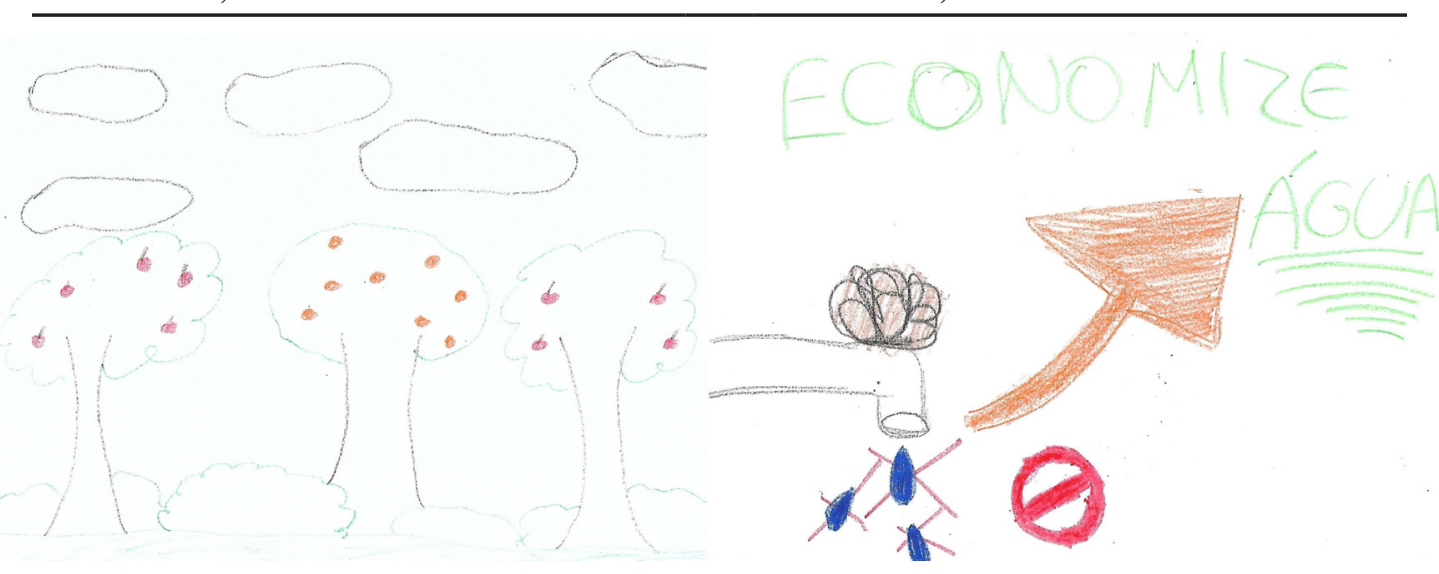

Dibujo clasificado en el nivel 3

Dibujo clasificado en el nivel 4

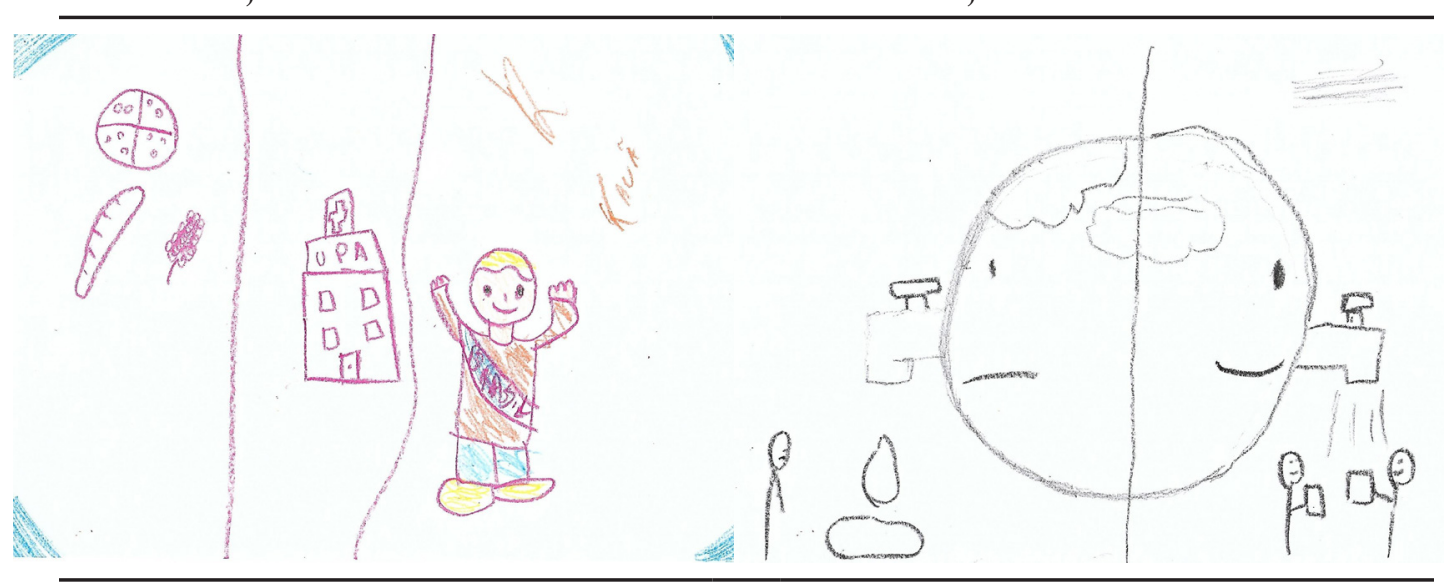

Fuente: Elaboración propia.

En la Tabla 2 podemos observar ejemplos con diferentes niveles de representaciones, desde aquellas en las que no se evidencian muchas relaciones entre los ODS (niveles 1 y 2), hasta niveles en los que emergen elementos del contexto local/regional (banda presidencial, sistema público de salud local) y relaciones causa y efecto, prescribiendo modos de cambio y acción en los cuales las personas se hacen partícipes. 


\section{Conclusiones}

Las discusiones y reflexiones durante los talleres — generadas gracias a la interpretación de kits con fotografías, obras de arte e informes_- permitieron observar la aparición de limitaciones, posibilidades y condicionantes relacionados con la sostenibilidad (su complejidad e incompletitud).

La estrategia de trabajar con esta estructura del taller trajo nuevos caminos hacia prácticas pedagógicas para que los participantes de la actividad puedan interpretar, reflexionar y dialogar con otros acerca de problemas cotidianos o específicos relacionados con demandas socioambientales. Las reflexiones colectivas permiten entender la necesidad de cambiar actitudes y acciones a críticas efectivas del panorama mundial actual, así como a la búsqueda de construcción de nuevos caminos colectivos y emancipadores.

La ausencia de representaciones de nivel 5 indica la necesidad de trabajar competencias en ambas escuelas para integrar diferentes campos conceptuales y niveles de abstracción, caracterizando límites pedagógicos a los planteamientos de sostenibilidad, lo que demanda procesos a mediano y a largo plazo. Además, revela que se requiere de procesos educativos orientados hacia una acción pedagógica comprometida con cambios socioambientales.

Lo anterior nos hace comprender que el taller debe completarse con algunas mejoras, por ejemplo, su corta durabilidad para abordar problemas tan complejos y extensos como los que aquí abordamos. En cuanto al límite metodológico, dado que las sesiones no fueron grabadas, algunas relaciones entre los ODS que fueron mencionadas de modo oral no quedaron registradas en los dibujos. En cuanto a condicionantes, en la mayoría de los dibujos hubo una falta de representación política, cuestiones relacionadas con la opresión o la resistencia. Sin embargo, se notó que para muchos de los participantes de ambas escuelas se trató de un proceso que permitió comprender el problema planteado acerca de la sostenibilidad, y una oportunidad para dialogar directamente respecto de los problemas ambientales, sociales y políticos a nivel local, marcados por sus contextos urbanos con procesos de exclusión.

De igual modo, queremos resaltar que durante el año la Escuela 2 había desarrollado con la Universidad Federal de Río de Janeiro un proyecto de colaboración relacionado con el tema, lo cual podría haber influenciado positivamente en la sofisticación de los dibujos. Lo anterior se condice con la distribución de los dibujos en los niveles 2 a 4 de las progresiones en las competencias representativas. En los dibujos de nivel 4 fue posible caracterizar compromisos individuales con cambios socioambientales, en los cuales el rol del estudiante como agente de cambio era parte del dibujo. Eso fue una potencialidad del taller y permite inferir que los estudiantes han representado dimensiones de la sostenibilidad a través de sus propias representaciones, caracterizando y superando su cotidiano urbano, complejo y vulnerable.

El artículo original fue recibido el 14 de mayo de 2020

El artículo revisado fue recibido el 7 de agosto de 2020

El artículo fue aceptado el 28 de agosto de 2020

\section{Referencias}

Acher, A., Arcà, M., \& Sanmartí, N. (2007). Modelling as a teaching-learning process for understanding materials. A case study in primary education. Science Education, 91, 398-418. https://doi.org/10.1002/sce.20196

Acosta, A. (2012). Buen vivir Sumak Kawsay. Una oportunidad para imaginar nuevos mundos. Quito: Abya Yala. 
Álvarez, N. (2013). Retrospectiva y reflexiones aproximadas acerca de la degradación del medio ambiente. Revista Dimensión Empresarial, 11(2), 26-35. Recuperado de http://www.scielo.org.co/pdf/diem/v11n2/v11n2a04.pdf

Alves, A. R. (2010). O conceito de hegemonia: De Gramsci a Laclau e Mouffe. Lua Nova: Revista de Cultura e Politica, 80, 71-96. https://doi.org/10.1590/s0102-64452010000200004

Bauman, Z. (2001). Modernidade líquida (1a edição). Rio de Janeiro: Jorge Zahar.

Bhaskar, R. (1997). A realist theory of science (2a edition). London: Verso.

Bliss, J., Monk, M., \& Orgborn, J. (1983). Exploratory qualitative analysis for educational research. Buckingham: Croom Helm.

Borges, F. (2012). Os gêneros textuais em cena: Uma análise crítica de duas concepçóes de gêneros textuais e sua aceitabilidade na educaçáo no Brasil. Revista Brasileira de Linguistica Aplicada, 12(1), 119-140. https://doi.org/10.1590/s1984-63982012000100007

Bourdieu, P. (2011). O campo político. Revista Brasileira de Ciência Política, 5, 193-216. https://dx.doi.org/10.1590/ S0103-33522011000100008

Buss, P. M., \& Pellegrini-Filho, A. (2007). A saúde e seus determinantes sociais. Physis: Revista de Saúde Coletiva, 17(1), 77-93. https://doi.org/10.1590/s0103-73312007000100006

Cerda, J. \& Villarroel, L. (2008). Evaluation of the interobserver concordance in pediatric research: The kappa coefficient. Revista Chilena de Pediatría, 79(1), 54-58. https://doi.org/10.4067/s0370-41062008000100008

Carneiro, E. (2005). Política ambiental e a ideologia do desenvolvimento sustentável. En A. Zhouri \& K. Laschefski (Eds.), A insustentável leveza da política ambiental: Desenvolvimento e conflitos socioambientais (pp. 27-47). Belo Horizonte: Autêntica.

Cosenza, A., Freire, L. M., Martins, I., \& Espinet, M. (2014). Relaçóes entre justiça ambiental, ensino de ciências e cidadania nas construçôes discursivas de professores em processos de formação continuada. Revista Brasileira de Pesquisa em Educação em Ciências, 14(2), 77-87. Recuperado de https://periodicos.ufmg.br/index.php/rbpec/article/view/4352

Diegues, A. C. (1992). Desenvolvimento sustentável ou sociedades sustentáveis: Da crítica dos modelos aos novos paradigmas. São Paulo em Perspectiva, 6(1-2), 22-29. Recuperado de http://www.michaeljonas.com.br/ meu\%20trabalho/fca_grad/Economia\%20II/Apo/Desenvolvimento\%20Sustentavel.pdf

Elisei, M. G. (2008). Diagnóstico da percepção ambiental através do desenho infantil. Taubaté: Cabral Editora e Livraria Universitária.

Fairclough, N. (1992). Discourse and social change. Oxford and Cambridge: Polity Press and Blackwell.

Fernández, L. y Gutiérrez, M. (2013) Bienestar social, económico y ambiental para las presentes y futuras generaciones. Información Tecnológica, 24(2), 121-130. https://doi.org/10.4067/s0718-07642013000200013

Figueiredo, T. F. (2020). Narrativas na formação docente em ciências: Um olhar a partir de uma disciplina de educação ambiental da Universidade Federal do Estado do Rio de Janeiro (UNIRIO). (Dissertaçáo. Núcleo de Tecnologia Educacional para a Saúde). Universidade Federal do Rio de Janeiro, Rio de Janeiro.

Figueiroa, T., Andrade, C., Mejía-Cáceres, M., Pedroso, K., \& Freire, L. (2019). Reflexóes sobre educação ambiental a partir das relaçôes entre arte, linguagem e cultura. Trabajo presentado en IX EREBIO RJ/ES - VII Encontro Regional de Ensino de Biologia RJ/ES (2606-2609), Rio de Janeiro: MGSC Editora.

Freire, L. \& Rodrigues, C. (2020). Formação de professores e educadores ambientais: Diálogos generativos para a práxis. Pesquisa em Educação Ambiental, 15(1), 106-125. https://doi.org/10.18675/2177-580x.2020-14666

Freire, L., Bozelli, R., Espinet, M., \& Martins, I. (2012). Discursos de educação ambiental produzidos por professores em formação continuada. Revista Brasileira de Pesquisa em Educação Ambiental em Ciências, 12, 93-110. Recuperado de https://periodicos.ufmg.br/index.php/rbpec/article/view/4232

Gadea, C. A. \& Scherer-Warren, I. (2005). A contribuição de Alain Touraine para o debate sobre sujeito e democracia latino-americanos. Revista de Sociologia e Política, 25, 39-45. https://doi.org/10.1590/s0104-44782005000200005

González-Gaudiano, E. J. (2005). Interdisciplinaridade e educação ambiental: Explorando novos territórios epistêmicos. En M. Sato \& I. Carvalho (Orgs.), Educação Ambiental: Pesquisa e desafios (pp. 119-133). Porto Alegre: Artmed.

González-Gaudiano, E. J. \& Lorenzetti, L. (2009). Investigação em educação ambiental na América Latina: Mapeando tendências. Educação em Revista, 25(3), 191-211. https://doi.org/10.1590/s0102-46982009000300010

González-Gaudiano, E. J. y Puente, J. C. (2010). El campo de la educación ambiental en la región latinoamericana. Rasgos, retos y riesgos Trayectorias, 12(31), 91-106. Recuperado https://www.redalyc.org/pdf/607/60717342006.pdf 
González Gaudiano, E. J., Meira-Cartea, P. A., y Martínez-Fernández, C. N. (2015). Sustentabilidad y universidad: retos, ritos y posibles rutas. Revista de la Educación Superior, 44(175), 69-93. https://doi.org/10.1016/j.resu.2015.09.002

Giddens, A. (2003). Modernidade e identidade (Trad. P. Dentzien). Rio de Janeiro: Jorge Zahar.

Gilbert, J. (2005). Visualization: A metacognitive skill in science and science education. En J. K. Gilbert (Ed.), Visualization in science education (pp. 9-27). London: Springer. https://doi.org/10.1007/1-4020-3613-2_2

Hamlin, C. L. (2000). Realismo crítico: Um programa de pesquisa para as Ciências Sociais. Dados, 43(2), 00. https://dx.doi.org/10.1590/S0011-52582000000200006

Harvey, D. (2003). Condição pós-moderna: Uma pesquisa sobre as origens da mudança cultural (12a edição). São Paulo: Loyola.

Hearn, G., Foth, M., \& Stevenson, T. (2011). Community Engagement for sustainable urban futures. Futures, 43(4), 357-360. https://doi.org/10.1016/j.futures.2011.01.002

Izquierdo, M. \& Adúriz-Bravo A. (2003). Epistemological foundations of school science. Science \& Education, 12, 27-43. https://doi.org/10.1023/A:1022698205904

Jatobá, S. U. S., Cidade, L. C. F., \& Vargas, G. M. (2009). Ecologismo, ambientalismo e ecologia política: Diferentes visōes da sustentabilidade e do território. Sociedade e Estado, 24(1), 47-87. https://doi.org/10.1590/s0102-69922009000100004

Justi, R. (2006). La enseñanza de las ciencias basada en la elaboración de modelos. Enseñanza de las Ciencias, 24(2), 173-184. Recuperado de https://www.raco.cat/index.php/Ensenanza/article/view/75824

Kon, A. (2007). Sobre a economia política do desenvolvimento e a contribuição dos serviços. Brazilian Journal of Political Economy, 27(1), 130-146. https://doi.org/10.1590/s0101-31572007000100007

Kozma, R. \& Russell, J. (2005). Students becoming chemists: Developing representational competence. En J. Gilbert (Ed.), Visualization in science education (pp. 121-146). Netherlands: Springer.

Kothari, A., Demaria, F., \& Acosta, A. (2014). Buen vivir, Degrowth and Ecological Swaraj: Alternatives to sustainable development and the Green Economy. Development, 57 (3-4), 362-375. https://doi.org/10.1057/dev.2015.24

Kothari, A. (2018). Eco-Swaraj vs. Global Eco-Catastrophe. Asia Pacific Perspectives, 15(2), 49-54. Recuperado de https://www.usfca.edu/sites/default/files/arts_and_sciences/center_for_asia_pacific_studies/3-kothari-eco-swaraj.pdf

Laclau, E. y Mouffe, C. (2004). Hegemonía y estrategia socialista: hacia una radicalización de la democracia. Buenos Aires: Fondo de Cultura Económica de Argentina.

Layrargues, P. \& Lima, G. (2014). As macrotendências político-pedagógicas da educação ambiental brasileira. Ambiente \& Sociedade, 17(1), 23-40. https://doi.org/10.1590/1809-44220003500

Le Grange, L. (2018) The notion of Ubuntu and the (Post)Humanist condition. En J. Petrovic, \& R. Mitchell (Eds.), Indigenous philosophies of education around the world (pp. 40-60). New York: Routledge.

Leff, E. (2002). Epistemologia ambiental (3a edição), São Paulo: Cortez.

Leff, E. (2007). Precisamos de uma nova racionalidade. SENAC e Educação Ambiental, 16(1), 8-12.

Lima, G. F. C. (2003). O discurso da sustentabilidade e suas implicaçôes para a educaçấo. Ambiente \& Sociedade, 6(2), 99-119. https://doi.org/10.1590/s1414-753×2003000300007

Lima, G. F. C. (2009). Educação ambiental crítica: Do socioambientalismo às sociedades sustentáveis. Educação e Pesquisa, 35(1), 145-163. https://doi.org/10.1590/s1517-97022009000100010

López-Pardo, I. L. (2012). Sostenibilidad 'débil' y 'fuerte' y democracia deliberativa: el caso de la Agenda 21 local de Madrid. Recuperado de: https://e-archivo.uc3m.es/bitstream/handle/10016/16270/tesis_lopez_pardo_2012. pdf?sequence $=1 \&$ isAllowed $=y_{-}$

López Ricalde, C. D., López Hernández, E. S., y Ancona Peniche, I. (2005). Desarrollo sustentable o sostenible: una definición conceptual. Horizonte Sanitario, 4(2), 28-34.

Malheiros, T. F., Philippi Jr., A., \& Coutinho, S. M. V. (2008). Agenda 21 Nacional e Indicadores de Desenvolvimento Sustentável: contexto brasileiro. Saúde e Sociedade, 17(1), 7-20. https://doi.org/10.1590/S0104-12902008000100002

Marin, A. A. (2006). A educação ambiental nos caminhos da sensibilidade estética. Revista Inter Ação, 31(2), 277-290. https://doi.org/10.5216/ia.v31i2.1260

Márquez, C., Izquierdo, M., y Espinet, M. (2003). Comunicación multimodal en la clase de ciencias: el ciclo del agua. Enseñanza de las Ciencias, 21(3), 371-386. Recuperado de https://core.ac.uk/download/pdf/38990751.pdf 
Martinho, L. R. \& Talamoni, J. L. B. (2007). Representaçôes sobre meio ambiente de alunos da quarta série do Ensino Fundamental. Ciência \& Educação (Bauru), 13(1), 1-13. https://doi.org/10.1590/s1516-73132007000100001

Meira, P. Á. (2009). Outra leitura da história da Educação Ambiental e algum apontamento sobre a crise do presente. AmbientalMente Sustentable, 4(8), 6-43. Recuperado de https://dialnet.unirioja.es/descarga/articulo/3171954.pdf

Merino, C. y García, A. (2019). Incorporación de realidad aumentada en el desarrollo de la visualización. Un estudio con estudiantes de secundaria en torno al modelo atómico. Pensamiento Educativo. Revista de Investigación Educacional Latinoamericana, 56(2), 1-23. https://doi.org/10.7764/pel.56.2.2019.6

Merino, C. \& Sanmartí, N. (2008). "How Young Children Model Chemical Change." Chemistry Education Research and Practice, 9(3): 196-207. https://doi.org/10.1039/b812408f

Nascimento, E. (2012). Trajetória da sustentabilidade: Do ambiental ao social, do social ao econômico. Estudos Avançados, 26(74), 51-64. https://doi.org/10.1590/s0103-40142012000100005

Nobre, C. A., Lahsen, M., \& Ometto, J. P (2008). Global environmental change research: Empowering developing countries. Anais da Academia Brasileira de Ciências, 80(3), 523-529. https://doi.org/10.1590/s0001-37652008000300012

Núnez, M. B., Castro, C. M., y Cartea, P. M. (2017). La educación ambiental en tiempos de crisis. ¿Dónde está cuando más se necesita? Ambiente \& Sociedade, 20(3), 139-158. https://doi.org/10.1590/1809-4422asoc0026v2032017

Organización de las Naciones Unidas, ONU. (1987). Nuestro futuro común: Informe de la Comisión Mundial sobre el Medio Ambiente y el Desarrollo (Informe Brundtland). Recuperado de http://www.ecominga.uqam.ca/ PDF/BIBLIOGRAPHIE/GUIDE_LECTURE_1/CMMAD-Informe-Comision-Brundtland-sobre-MedioAmbiente-Desarrollo.pdf

Organização das Naçóes Unidades, ONU. (2015). Conheça os novos 17 Objetivos de Desenvolvimento Sustentável da ONU: Os ODS devem ser implementados por todos os paises do mundo durante os próximos 15 anos, até 2030. Recuperado de http://www.funag.gov.br/index.php/pt-br/2015-02-12-19-38-42/531-conheca-os-novos-17-objetivos-dedesenvolvimento-sustentavel-da-onu

Payne, P. G. (2018). The framing of Ecopedagogy as/in scapes: Methodology of the issue. The Journal of Environmental Education, 49(2), 71-87. https://doi.org/10.1080/00958964.2017.1417227

Pedrini, A., Costa, E. A., \& Ghilardi, N. (2010). Percepção ambiental de crianças e pré-adolescentes em vulnerabilidade social para projetos de educação ambiental. Ciência \& Educação (Bauru), 16(1), 163-179. https://doi.org/10.1590/s1516-73132010000100010

Profice, C. C., Pinheiro, J. Q., Fandi, A. C., y Gomes, A. R. (2013). Janelas para a percepção infantil de ambientes naturais. Psicologia em Estudo, 18(3), 529-539. https://doi.org/10.1590/s1413-73722013000300014

Rodríguez, I. y Héctor, G. (2006). El discurso del desarrollo sustentable en América Latina. Revista Venezolana de Economía y Ciencias Sociales, 12(2), 37-63. Recuperado de https://www.redalyc.org/pdf/177/17712202.pdf

Sachs, I. (1993). Estratégias de transição para o século XXI. En M. Bursztyn, A. Mendes, I. Sachs, C. Buarque, L. Dowbor, R. C. Aguiar, B. Becker, \& P. Leitão (Eds.), Para pensar o desenvolvimento sustentável (pp. 29-56). São Paulo: Brasiliense.

Sachs J. (2012). From millennium development goals to sustainable development goals. The Lancet, 379(9832), 2206-2211. https://doi.org/10.1016/s0140-6736(12)60685-0

Sauvé, L. (2010). Educación científica y educación ambiental: un cruce fecundo. Enseñanza de las Ciencias, 18(1), 5-17. Recuperado de https://www.raco.cat/index.php/Ensenanza/article/view/189092

Scott, P. \& Jewitt., C. (2003). The role of talk, action and visual communication in the teaching and learning of science. School Science Review, 84(308), 117-124.

Selley N. J. (2000). Students' spontaneous use of a particulate model for dissolution. Research in Science Education, 30(4), 389-402. https://doi.org/10.1007/bf02461558

Taylor S. J. y Bodgan R. (1994) Introducción a los métodos cualitativos de investigación. Barcelona: Paidós.

Teodoro, P. (2012). O sofisma da sustentabilidade urbana. Mercator, 11(24), 101-113. https://doi.org/10.4215/rm2012.1124.0007

Trejos-Benavides, E. (2012) Estrategias de desarrollo económico en América Latina: una visión global. Tecnología en Marcha, 25(6), 57-75. https://doi.org/10.18845/tm.v25i6.647 
Torales, M. (2013). A inserção da educação ambiental nos currículos escolares e o papel dos professores: Da ação escolar a ação educativo-comunitária como compromisso político-ideológico. REMEA-Revista Eletrônica do Mestrado em Educação Ambiental, 0, 1-17. Recuperado de https://periodicos.furg.br/remea/article/view/3437

Vanhulst, J. y Beling, A. E. (2013). El buen vivir: una utopía latinoamericana en el campo discursivo global de la sustentabilidad.Polis, RevistaLatinoamericana, 12(36),497-522.https://doi.org/10.4067/s0718-65682013000300022

Wade, R. H. (2004). Is globalization reducing poverty and inequality? World Development, 32(4), 567-589. https://doi.org/10.1016/j.worlddev.2003.10.007

Yin, R. K. (2003). Case study research. Design and methods. California: Sage Publications.

Ziman, J. (2001). Real Science: what it is? and what it means? Cambridge: Cambridge University Press.

\section{Anexo 1}

Kits distribuidos a los estudiantes con las imágenes y sus fuentes.

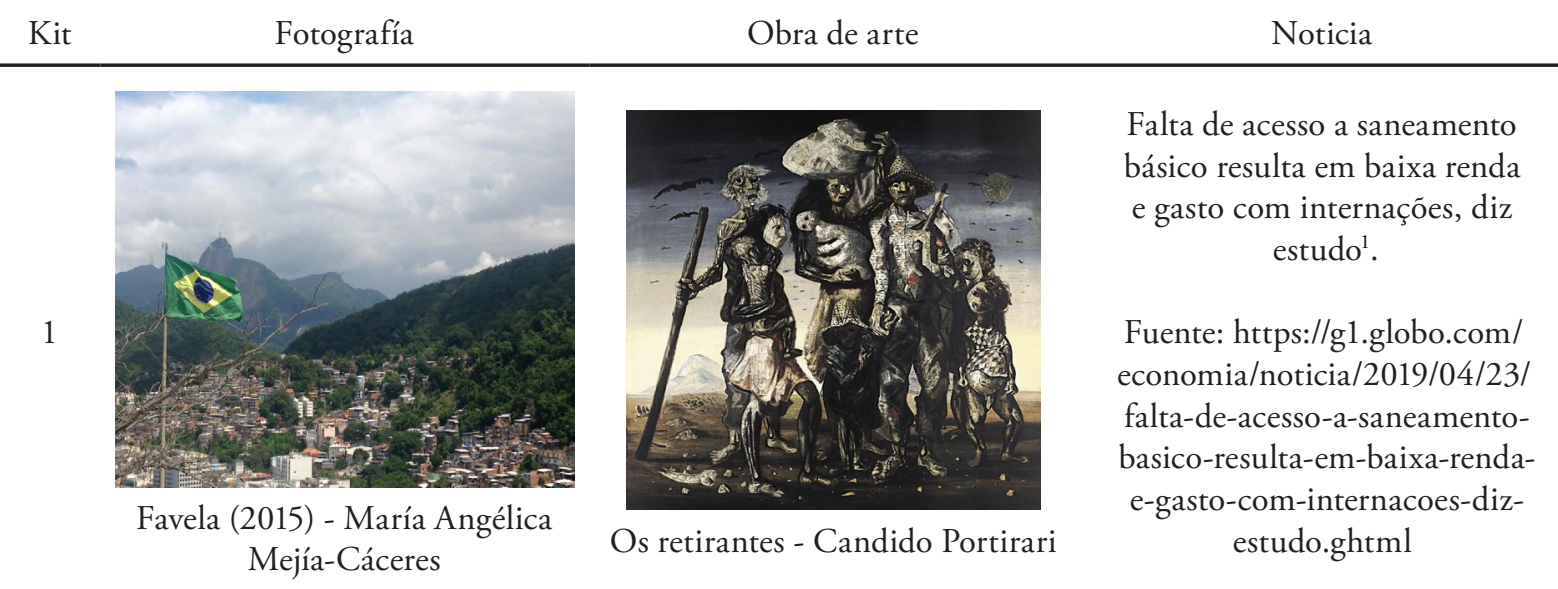

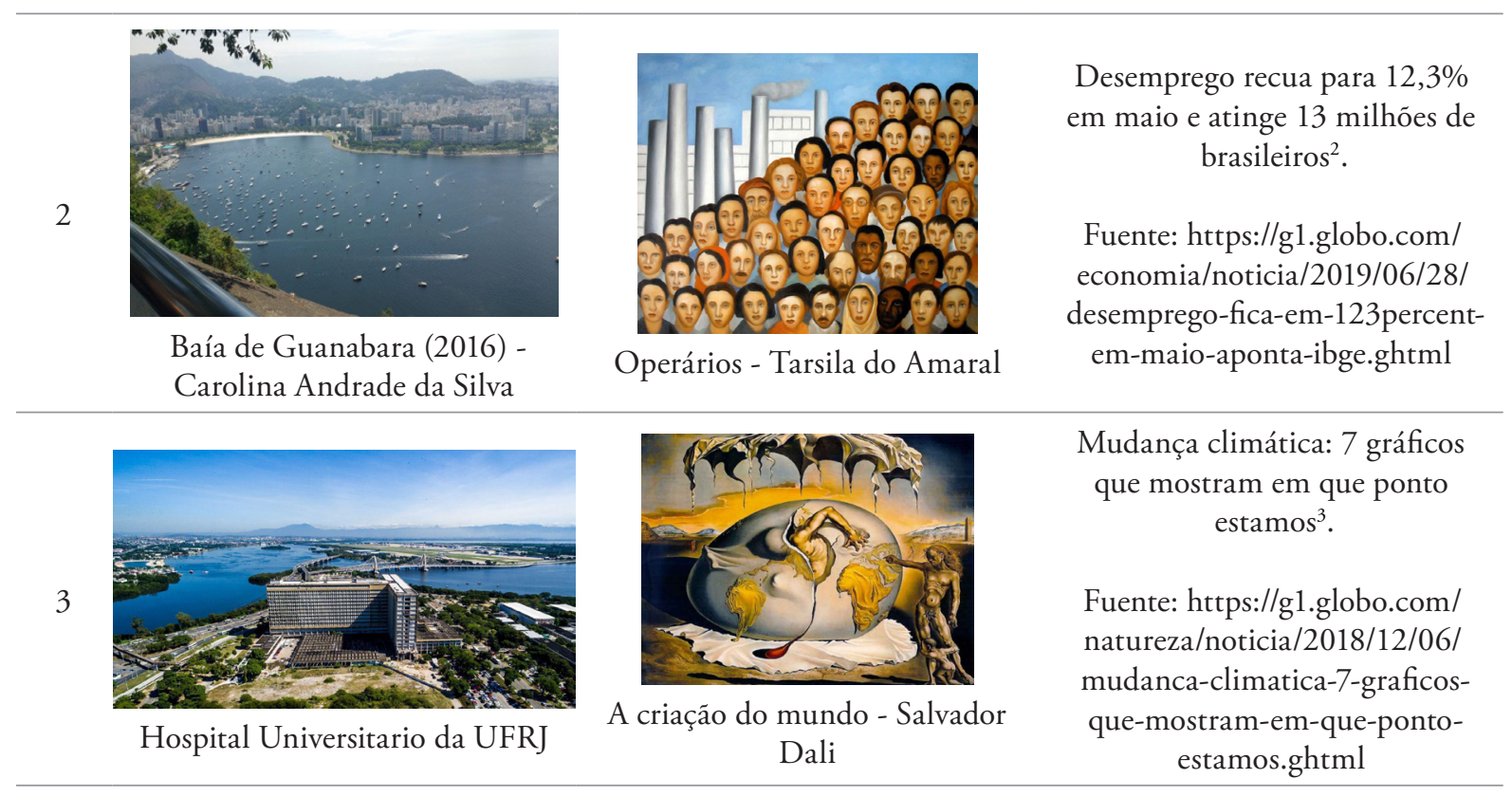

1. Traducción nuestra: La falta de acceso al saneamiento básico resulta en bajos ingresos y gastos en hospitalizaciones, según un estudio.

2. Traducción nuestra: El desempleo cae al 12,3\% en mayo y llega a 13 millones de brasileños.

3. Traducción nuestra: Cambio climático: 7 gráficos que muestran dónde estamos. 
4

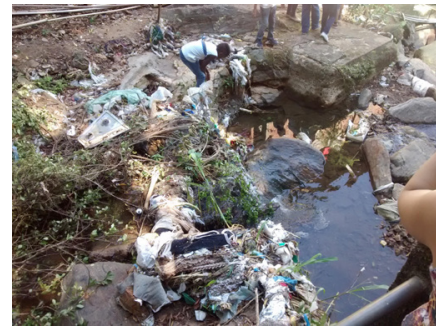

Rio Cascata (2016) - Tainá

Figueroa Figueiredo

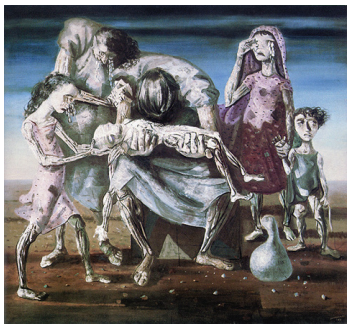

Criança morta - Candido Portirari
Estes dados mostram que a fome ainda é um problema no Brasil ${ }^{4}$.

Fuente: https://super.abril.com. br/sociedade/por-que-ainda-naoda-para-afirmar-que-nao-existefome-no-brasil/
5

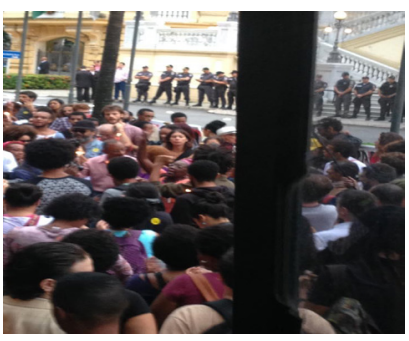

Manifestação (2015) - María Angélica Mejía-Cáceres

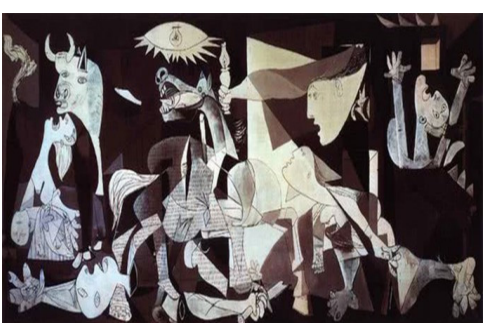

Guernica - Pablo Picasso
Líbia: ataque com carro-bomba mata três funcionários da ONU em Bengazi5.

Fuente: https://nacoesunidas.org/ libia-ataque-com-carro-bombamata-tres-funcionarios-da-onuem-bengazi/

Fuente: Elaboración propia.

4. Traducción nuestra: Estos datos muestran que el hambre sigue siendo un problema en Brasil.

5. Traducción nuestra: Libia: El ataque con coche bomba mata a tres funcionarios de la ONU en Bengazi. 